\title{
Rosemary Aromatization of Extra Virgin Olive Oil and Process Optimization Including Antioxidant Potential and Yield
}

\author{
Erkan Karacabey*, Gulcan Ozkan, Latife Dalgıc, Saliha Onur Sermet
}

${ }^{I}$ Food Engineering Department, Engineering Faculty, Süleyman Demirel University, 32260 Issparta, Turkey

\section{A R T I C L E I N F O}

Article history:

Received 06 April 2016

Accepted 20 May 2016

Available online, ISSN: 2148-127X

Keywords:

Antioxidants

Aromatization

Olive oil

Pigments

Response surface methodology

Corresponding Author:
E-mail: erkankaracabey@sdu.edu.tr \begin{abstract}
A B S T R A C T
Aromatization of olive oil especially by spices and herbs has been widely used technique throughout the ages in Mediterranean diets. The present study was focused on aromatization of olive oil by rosemary (Rosmarinus officinalis L.). Aromatization process was optimized by response surface methodology as a function of malaxation's conditions (temperature and time). According to authors' best knowledge it was first time for examination of oil yield performance with antioxidant potential and pigments under effect of aromatization parameters. For all oil samples, values of the free acidity, peroxide, $\mathrm{K}_{232}$ and $\mathrm{K}_{270}$ as quality parameters fell within the ranges established for the highest quality category "extra virgin oil". Oil yield ( $\mathrm{mL}$ oil $/ \mathrm{kg}$ olive paste) changed from 158 to 208 with respect to design parameters. Total phenolic content and free radical scavenging activity as antioxidant potential of olive oil samples were varied in the range of $182.44-348.65 \mathrm{mg}$ gallic acid equivalent $/ \mathrm{kg}$ oil and $28.91-88.75 \%$ inhibition of 2,2-Diphenyl-1-picrylhydrazyl-(DPPH•), respectively. Total contents of carotenoid, chlorophyll and pheophytin a as pigments in oil samples were found to be in between $0.09-0.48 \mathrm{mg}$ carotenoid $/ \mathrm{kg}$ oil, $0.11-0.96 \mathrm{mg}$ chlorophyll $/ \mathrm{kg}$ oil, $0.15-4.44 \mathrm{mg}$ pheo $\alpha / \mathrm{kg}$ oil, respectively. The proposed models for yield, pigments and antioxidant potential responses were found to be good enough for successful prediction of experimental results. Total phenolics, carotenoids and free radical scavenging activity of aromatized olive oil and oil yield were maximized to gather and optimal conditions were determined as $25^{\circ} \mathrm{C}, 84 \mathrm{~min}$, and $2 \%$ (Rosemary/olive paste; w/w).
\end{abstract}

\section{Introduction}

Virgin olive oil is a popular product widely used throughout the ages in the Mediterranean cuisine and is appreciated for its delicious taste and aroma, as well as for its nutritional benefits (Moldão-Martins et al., 2004; Morales et al., 2000; Stark and Madar, 2002) primarily related to its balanced fatty acid composition and the presence of considerable amounts of natural antioxidants (Moldão-Martins et al., 2004). Its preventive and healing actions on cardiovascular diseases, certain types of cancer, and other chronic diseases have been associated with antioxidant potential of olive oil (Boskou et al., 2006; Jacotot, 1994).

In recent years, consumers have focused on new foods including different spices and herbs because of new trends in local and traditional markets. Especially virgin olive oils flavored with spices or herbs have been taken increasing interest because of their health promoting effect with antioxidant potential against oxidation reactions beside of flavoring properties (Boskou et al., 2006). In order to produce flavored olive oil (generally virgin olive oil), fresh or dried vegetables, herbs, spices or other fruits and/or their aroma, essential oils and extracts can be added in olive oil in order to improve the nutritional value, enrich the sensory characteristics and increase antioxidant potential or shelf-life (Lagouri and
Boskou, 1996; Nouhad and Tsimidou, 1998; Tsimidou, 1998).

Rosemary (Rosmarinus officinalis L.) belonging to the family of Lamiaceae, is one of the common herb for olive oil aromatization, especially in the Mediterranean region. High popularity of rosemary is implicated in health beneficial effect, nutritional potential with high antioxidant activity (Chipault et al., 1952), thus researchers and consumers' interests have been increasing and it is focused on in different studies. Damechki et al. (2001) investigated the phenolic compound potential of aromatized olive oil and found that oil aromatized by rosemary had higher phenolic content than the nonaromatized ones. Moreover, the oxidative stability of oil products was studied and results indicated that aromatized olive oil displayed better stability compared to oil processed without aromatic plant (Rached et al., 2014; Tsimidou, 1998).

Flavored or aromatized olive oils have been generally produced as boutique and carried out through different techniques. Infusion of plant material, mixing of essential oil and aromatic plant extract with oil are available common techniques used in flavored olive oil industry. These techniques include some disadvantages like turbidity, over dosage (Gambacorta et al., 2007), co- 
extraction of undesirable constituents (waxes and bitters) (Moldão-Martins et al., 2004), production necessity of essential oil and solvent free plant extract. Additionally other aromatization techniques are based on directly addition of ground and/or whole plant materials into olive or olive paste in crushing and malaxation steps, respectively. However, these methods also cause some problems which should be required to be solved to get standardize flavored olive oil. In crushing step it is not easy to adjust concentration of aromatic plant addition due to non-homogenous distribution of leaves, woody parts and limited time for transition. In malaxation step kneading parameters are significant on transition of target compounds from natural source to olive oil (Aguilera et al., 2010; Inarejos-García et al., 2009; Kalua et al., 2006). Studies have indicated that temperature and time variables in a malaxation step are important and both should be considered and adjusted well (Inarejos-García et al., 2009; Kalua et al., 2006; Ranalli et al., 2003b). Malaxation parameters, temperature and time are reported to be significant due to their effects on "coalescence phenomena" where the small oil droplets merges into large drops (diameter $>30 \mu \mathrm{m}$ ), thus oil separation from both colloids and water droplets occurs (Clodoveo, 2012). Temperature and time of malaxation step should be examined for any optimization study of olive oil production due to their direct effects on the final product in terms of productivity, composition and quality. Literature survey indicates that there are studies about aromatized olive oils. However according to authors' best knowledge there is no any study covering optimization of malaxation parameters and plant material in terms of extraction yield of olive oil having high quality, pigments and antioxidant potential.

In the present study, it was aimed to examine the change in composition of olive oil with rosemary addition and to optimize aromatization process considering virgin olive oil at better quality, higher yield and functional potential.

\section{Material and Method}

\section{Material}

Commercial olive cultivar of Gemlik was supplied from local producer located in Manavgat, Antalya, Turkey. As an aromatic plant, rosemary (Rosmarinus officinalis L.) was cultivated in the research and application fields of Agricultural Faculty of Süleyman Demirel University, Isparta, Turkey. Rosemary was ground and sieved from $1 \mathrm{~mm}$-sieve. Physical properties of olive fruits including width and length of fruit $(\mathrm{cm})$, weights of fruits, and moisture and oil contents (by Soxhlet method on dry weight basis) of olives (\%) were determined after samples arrived. All measurements were carried out triplicate for each sample. Mean values of physical properties of olive fruits including width, length, and weight of fruits and moisture and oil contents were found to be $15.3 \pm 0.934 \mathrm{~mm}, 19.8 \pm 1.360 \mathrm{~mm}, 3.27 \pm$ $0.4560 \mathrm{~g}, 43.5 \pm 0.087 \%$, and $57.080 \pm 0.010 \%$, respectively.

Extraction of olive oil: The olive samples were mechanically processed at laboratory conditions by using a disk miller (Hakki Usta Machinery, Aydin Turkey), malaxor (Hakki Usta Machinery, Aydin Turkey) and a hydraulic-hand press (Arıkan Machinery, Isparta, Turkey). Leaves were removed and one $\mathrm{kg}$ of olive fruits with stones was crushed. Ground rosemary, sieved from 1 mm-sieve, and were mixed with crushed olive fruits at certain ratios in a malaxor and kneading was carried for specified temperature and time pairs (Table 1). Amount of rosemary addition (\%) and malaxation conditions (temperature-time) were adjusted according to experimental design of malaxation process (Table 1).

Table 1 Three-factor, five-level central composite design used for RSM

\begin{tabular}{c|cccc}
\hline \multirow{2}{*}{ Standard order ${ }^{\mathrm{a}}$} & \multirow{2}{*}{ Run order $^{\mathrm{b}}$} & Factor $1, \mathrm{X}_{1}$ & Factor $2, \mathrm{X}_{2}$ & Factor 3, $\mathrm{X}_{3}$ \\
\cline { 3 - 5 } 10 & 1 & Temperature $\left({ }^{\circ} \mathrm{C}\right)$ & Time $(\mathrm{min})$ & Rosemary conc. $(\%)$ \\
\hline 1 & 2 & $45(1.68)$ & $50(0)$ & $1.000(0)$ \\
5 & 3 & $29(-1)$ & $30(-1)$ & $0.405(-1)$ \\
12 & 4 & $29(-1)$ & $30(-1)$ & $1.595(1)$ \\
8 & 5 & $35(0)$ & $83.6(1.68)$ & $1.000(0)$ \\
13 & 6 & $41(1)$ & $70(1)$ & $0.000(-1.68)$ \\
3 & 7 & $35(0)$ & $50(0)$ & $0.405(-1)$ \\
15 & 8 & $29(-1)$ & $70(1)$ & $1.000(0)$ \\
16 & 9 & $35(0)$ & $50(0)$ & $1.000(0)$ \\
7 & 10 & $35(0)$ & $50(0)$ & $1.595(1)$ \\
6 & 11 & $29(-1)$ & $70(1)$ & $1.595(1)$ \\
9 & 12 & $41(1)$ & $30(-1)$ & $1.000(0)$ \\
18 & 13 & $25(-1.68)$ & $50(0)$ & $1.000(0)$ \\
4 & 14 & $35(0)$ & $50(0)$ & $0.405(-1)$ \\
14 & 15 & $41(1)$ & $70(1)$ & $2(1.68)$ \\
11 & 16 & $35(0)$ & $50(0)$ & $1.000(0)$ \\
17 & 17 & $35(0)$ & $16.4(-1.68)$ & $1.000(0)$ \\
2 & 18 & $35(0)$ & $50(0)$ & $0.405(-1)$ \\
\hline
\end{tabular}


After malaxation, $1 \mathrm{~kg}$ of olive paste with and without rosemary was packed in fabrics of four layers and placed in a hand press cell to separate oil from pomace. Pressure was gradually increased up to 60 bar, system was kept for 5 min under that pressure. Separated aromatized and nonaromatized oil were filtered through anhydrous sodium sulphate and cotton layer and stored in amber glass bottles at $4{ }^{\circ} \mathrm{C}$ until being analyzed.

Quality parameters of aromatized olive oil: Free acidity of oil sample was determined by the AOCS (1989) official method and results were given as an equivalent of oleic acid (\%). The AOCS (1999) official method was proposed for determination of peroxide value $\left(\mathrm{meq} \mathrm{O}_{2} / \mathrm{kg}\right.$ oil) of oil sample. UV extinction coefficient $\mathrm{K}_{232}$ and $\mathrm{K}_{270}$ were determined in accordance with the Alimentarius (2001). All measurements were carried out in triplicate for each sample.

Determination of chemical properties: Extraction procedures of total chlorophyll and carotenoid from olive oil were carried out according to Minguez-Mosquera et al. (1991) method, chlorophyll and carotenoid fractions in the absorption spectrum were determined at 670 and 470 $\mathrm{nm}$, respectively, using a spectrophotometer (T70 + UV/VIS spectrophotometer, PG Instruments, England). Thus, total chlorophyll (in $\mathrm{mg} / \mathrm{kg}$ ) and total carotenoid (in $\mathrm{mg} / \mathrm{kg}$ ) contents were calculated by using Equation 1 and 2 , respectively. Pheophytin a $(\mathrm{mg} / \mathrm{kg}$ oil as Pheo $\alpha)$ was calculated using Equation 3; where $\mathrm{A}_{\lambda}$ and $\mathrm{L}$ were the absorbance and the spectrophotometer cell thickness (10 $\mathrm{mm}$ ), respectively (Pokorny et al., 1995).

Chlorophyll $=\left(\mathrm{A}_{670} \times 10^{6}\right) /(613 \times 100 \times \mathrm{L})$
Carotenoid, $\left(\mathrm{A}_{470} \times 10^{6}\right) /(2000 \times 100 \times \mathrm{L})$
Pheophytin a $=345.3\left[\mathrm{~A}_{670}-\left(\mathrm{A}_{630}+\mathrm{A}_{710}\right) / 2\right] / \mathrm{L}$

The total phenol (TP) content of the extract was determined according to the Folin-Ciocalteu spectrophotometric (T70+UV/VIS spectrophotometer, PG Instruments, England) method at $765 \mathrm{~nm}$ (Singleton and Rossi, 1965), using a gallic acid calibration curve $\left(R^{2}=0.999\right)$. The results were expressed as milligrams of gallic acid per kilogram of oil.

Free radical scavenging activity of oil was measured using 2,2-Diphenyl-1-picrylhydrazyl-(DPPH•) free radical scavenging method according to Dorman et al. (2003). A $50 \mu \mathrm{L}$ aliquot of olive oil phenolic extract, in Tris- $\mathrm{HCl}$ buffer (50 mM, pH 7.4), was mixed with $450 \mu \mathrm{L}$ of Tris- $\mathrm{HCl}$ buffer $(50 \mathrm{mM})$ and $1.0 \mathrm{~mL}$ of DPPH $(0.1$ $\mathrm{mM}$, in methanol). After 30 minutes incubation in darkness and at ambient temperature, the resultant absorbance was recorded at $517 \mathrm{~nm}$. The percentage inhibition was calculated using the following equation (Eq. 4);

$$
\begin{aligned}
& \text { Inhibition }(\%)=[(\mathrm{AC}-\mathrm{AS}) / \mathrm{AC}] \times 100 \\
& \mathrm{AC}=\mathrm{Abs} \text { of control } \\
& \mathrm{AS}=\mathrm{Abs} \text { of sample }
\end{aligned}
$$

All spectrophotometric analyses were repeated three times for each extract.

\section{Experimental Design}

A central composite design was selected for optimization of malaxation conditions of temperature, time and rosemary addition each at five levels with 18 runs including four central points. Independent variables were temperature $\left(\mathrm{X}_{1}\right)$, time $\left(\mathrm{X}_{2}\right)$ and rosemary concentration $\left(\mathrm{X}_{3}\right)$. The levels of independent process variables and corresponding coded values were given in Table 1. Dependent variables were also total phenolic $\left(\mathrm{Z}_{1}\right)$, total carotenoid $\left(\mathrm{Z}_{2}\right)$, chlorophyll $\left(\mathrm{Z}_{3}\right)$, Pheo $\alpha\left(\mathrm{Z}_{4}\right)$, free radical scavenging activity (DPPH) $\left(Z_{5}\right)$ and olive oil yield $\left(\mathrm{Z}_{6}\right)$. Response surface methodology (RSM) was used for optimization using Minitab Software (Minitab 16.1.1). Full quadratic second order regression model was used for the prediction of process (Eq. 5).

$$
Z=\beta_{0}+\sum_{i=1}^{3} \beta_{i} X_{i}+\sum_{i=1}^{3} \beta_{i i} X_{i}^{2}+\sum_{i=1}^{2} \sum_{j=i+1}^{3} \beta_{i j} X_{i} X_{j}
$$

Where;

$\mathrm{Z}$ was the dependent variable, the $\mathrm{X}$ was the independent variables, $\beta_{0}$ was the constant coefficient, $\beta_{i}$, was the linear coefficient (main effect), $\beta_{\mathrm{ii}}$ was the quadratic coefficient and $\beta_{\mathrm{ij}}$ was the two factors interaction coefficient. Response surfaces of the predicted values obtained by proposed models were plotted in the studied variable ranges by Sigma Plot Software (SPSS Inc., Chicago, IL). Model adequacy was evaluated by considering parameters of $\mathrm{R}^{2}$ value, adjusted- $\mathrm{R}^{2}$ value, mean square error (MSE) of regression and lack-of-fit test.

\section{Results and Discussion}

In this study, aromatization of olive oil with rosemary was investigated to figure out its influence on olive oil yield, antioxidant potential and pigments as well as quality parameters (Table 2 and 3 ).

Quality parameters of aromatized olive oil: According to EU-regulations olive oils are classified with respect to free acidity and some physicochemical analyses including peroxide, $\mathrm{K}_{232}$ and $\mathrm{K}_{270}$. As shown in Table 2, free acidity (\% oleic acid), peroxide (meq $\mathrm{O}_{2} / \mathrm{kg}$ oil), $\mathrm{K}_{232}$ and $\mathrm{K}_{270}$ of aromatized olive oil samples were varied in the range of $0.50-0.78,9.22-17.94,1.49-2.08$ and $0.11-0.22$, respectively. Values of these analytical quality parameters for all aromatized oil samples fell within the ranges (free acidity: $0.8 \%$, peroxide value: 20 meq $\mathrm{O}_{2} / \mathrm{kg}$ oil, $\mathrm{K}_{232}$ and $\mathrm{K}_{270}$ values: 2.50 and 0.22 ) established for the highest quality category "extra virgin olive oil". These quality parameters were affected by malaxation conditions (temperature and time) and rosemary. Aromatization at higher temperatures and times had significant influence on free acidity, peroxide value, $\mathrm{K}_{232}$ and $\mathrm{K}_{270}$. Similarly an increase in amount of rosemary in olive paste ended up an increase in values of these quality parameters (Table 2). Variation in peroxide value with rosemary could be attributed to the transition of compounds from aromatic plant to olive oil during malaxation step. Literature results are also coincident with our ones. Malheiro et al. (2011) 
have studied the effect of olive leaves addition on oil quality indices and an increase in free acidity was observed related to amount of plant material. Ayadi et al. (2009) have studied the physico-chemical changes in extra virgin olive oil aromatized by different plants and increased peroxide value of oil product has been reported.

Marked effect of aromatic plant may also be strengthened by temperature accelerating the transition of these compounds from plant matrix to the olive oil. Additionally possible intensification of the primary oxidation processes responsible for the increase in peroxide value may also be as a result of temperature elevation. Clodoveo (2012) has mentioned the adverse temperature effect on peroxide value of olive oil. Similarly Abenoza et al. (2013) reported the requirement of well control of malaxation temperature due in part to its effect on oil characteristics and lower temperature values were advised. Time for malaxation step also resulted in an alteration in peroxide value. Change in peroxide value with process time could be associated with the intensification of oxidation phenomena as a consequence of a prolonged process. Ranalli et al. (2003b) and Kalua et al. (2006) have also examined the relation between malaxor conditions and olive oil quality, and they reported compatible results with the present ones.

Yield of aromatized olive oil: Experimental results indicated marked change in oil yield with process parameters $\quad(\mathrm{P} \leq 0.05) \quad$ (Table 4). When oil yield performance was investigated for processes at lower temperature levels, increasing rosemary amount promoted oil release form olive paste. However adverse effect of rosemary addition on oil yield was seen when rosemary level exceeded 1\% (w/w) (Figure 1). Higher levels (> 1\%) of rosemary amount increased oil yield when elevated temperature level was selected (Figure 1). Positive influence of rosemary on oil release may be attributed to increased drain channels by this plant material's fibers behaved like coadjuvants. Some technological coadjuvants have been successfully used for better performance of oil extraction (Espínola et al., 2009; Fernández Valdivia et al., 2008; Ranalli et al., 2003b). In another study plant origin fiber was directly used to examine its influence on oil extraction performance and an increase in yield was reported (Di Giovacchino, 1990). But no available data for olive oil aromatization with herbs having high fiber contents during malaxation step has been reported in literature related to oil yield change. As can be seen from Table 4 only interaction of temperature with rosemary amount was significant $(\mathrm{P} \leq 0.001)$ whereas no change being related to temperature was seen in oil yield $(\mathrm{P}>0.05)$. There are studies related to time effect on olive oil yield in literature (Espínola et al., 2011; Inarejos-García et al., 2009; Kalua et al., 2006; Ranalli et al., 2003a; Ranalli et al., 2003b). In these studies prolonged process was reported to improve oil yield, especially at elevated temperature levels. However no reported result presented about time influence on yield of aromatized olive oil with herbs in malaxation step. In present one, malaxation time significantly changed oil yield $(\mathrm{P} \leq 0.05)$ and this effect was found to be temperature dependent (Figure 2) (Table 4). Although time promoted oil release at low temperature levels, its influence was changed with temperature rise and oil yield decreased. Time and temperature interaction was in contrast to the results given in literature studies above. This adverse effect of time could be associated with possible reformation of oil/water and/or solid matrix/oil emulsions as a consequence of prolong malaxation process.

Table 2 Quality parameters of aromatized oil

\begin{tabular}{c|cccc}
\hline${\text { Run } \text { order }^{\mathrm{a}}}^{\mathrm{a}}$ & Peroxide value $^{\mathrm{b}}$ & Free acidity $^{\mathrm{c}}$ & $\mathrm{K}_{232}$ & $\mathrm{~K}_{270}$ \\
\hline 1 & 13.51 & 0.690 & 1.99 & 0.20 \\
3 & 10.35 & 0.590 & 1.66 & 0.15 \\
4 & 11.70 & 0.690 & 2.08 & 0.22 \\
5 & 15.09 & 0.640 & 1.81 & 0.19 \\
6 & 17.94 & 0.733 & 2.06 & 0.22 \\
7 & 9.22 & 0.497 & 1.49 & 0.11 \\
8 & 13.11 & 0.580 & 1.60 & 0.16 \\
9 & 13.30 & 0.673 & 1.85 & 0.19 \\
10 & 13.35 & 0.650 & 1.88 & 0.21 \\
11 & 15.53 & 0.687 & 1.99 & 0.21 \\
13 & 14.06 & 0.743 & 2.04 & 0.17 \\
14 & 11.92 & 0.613 & 1.77 & 0.16 \\
15 & 13.65 & 0.643 & 1.75 & 0.14 \\
17 & 14.85 & 0.583 & 1.58 & 0.22 \\
\end{tabular}

${ }^{\mathrm{a}}$, Randomized. ${ }^{\mathrm{b}}$, meq $\mathrm{O}_{2} / \mathrm{kg}$ oil. ${ }^{\mathrm{c}}, \%$ oleic acid equivalent. 
Table 3 Experimental results of investigated responses for corresponding trial.

\begin{tabular}{c|cccccc}
\hline${\text { Run } \text { order }^{\mathrm{a}}}^{\mathrm{a}}$ & Total Phenolic $^{\mathrm{b}}$ & Carotenoid $^{\mathrm{c}}$ & Chlorophyll $^{\mathrm{c}}$ & ${\text { Pheo } \alpha^{\mathrm{c}}}^{\mathrm{c}}$ & DPPH $^{\mathrm{d}}$ & Oil Yield $^{\mathrm{e}}$ \\
\hline 1 & 312.87 & 0.37 & 0.73 & 2.83 & 88.19 & 205 \\
3 & 193.12 & 0.15 & 0.19 & 0.48 & 28.91 & 168 \\
4 & 348.65 & 0.30 & 0.34 & 1.60 & 88.75 & 207 \\
5 & 267.88 & 0.33 & 0.51 & 2.16 & 88.23 & 186 \\
6 & 348.12 & 0.48 & 0.96 & 4.44 & 88.41 & 165 \\
7 & 182.44 & 0.09 & 0.11 & 0.15 & 38.15 & 158 \\
8 & 196.26 & 0.15 & 0.17 & 0.59 & 67.14 & 168 \\
9 & 284.37 & 0.29 & 0.43 & 1.64 & 88.14 & 193 \\
10 & 327.36 & 0.32 & 0.50 & 1.69 & 88.41 & 201 \\
11 & 328.56 & 0.39 & 0.59 & 2.38 & 88.45 & 204 \\
12 & 300.39 & 0.37 & 0.61 & 2.51 & 88.36 & 175 \\
13 & 262.88 & 0.20 & 0.22 & 1.18 & 88.32 & 192 \\
14 & 319.21 & 0.26 & 0.36 & 1.64 & 88.14 & 200 \\
15 & 210.14 & 0.19 & 0.28 & 1.27 & 74.63 & 172 \\
16 & 240.98 & 0.42 & 0.66 & 3.41 & 88.23 & 1.10 \\
17 & 311.20 & 0.18 & 0.20 & 1.82 & 88.14 & 88.14 \\
18 & 339.24 & 0.26 & 0.41 & 0.73 & 82.65 & 193 \\
\hline
\end{tabular}

${ }^{\mathrm{a}}$, Randomized. ${ }^{\mathrm{b}}, \mathrm{mg}$ gallic acid equivalent/kg oil. ${ }^{\mathrm{c}}, \mathrm{mg} / \mathrm{kg}$ oil. ${ }^{\mathrm{d}}, 2,2$-Diphenyl-1-picrylhydrazyl-(DPPH•) free radical scavenging activity, $\%$, ${ }^{\mathrm{e}}, \mathrm{mL}$ oil/kg olive paste.

Table 4 Regression coefficients of predicted models for the investigated responses of virgin olive oil aromatized by rosemary.

\begin{tabular}{|c|c|c|c|c|c|c|}
\hline \multirow{2}{*}{ Variable } & \multicolumn{6}{|c|}{ Coefficients } \\
\hline & Total Phenolic & Carotenoid & Chlorophyll & Pheo $\alpha$ & DPPH & OilYield \\
\hline$\beta_{0}$ & $305.59^{* * * *}$ & $0.272^{* * *}$ & $0.412^{* * * *}$ & $1.679^{\text {**** }}$ & $87.05^{* * *}$ & $197.276^{* * *}$ \\
\hline$\beta_{1}$ & $12.87^{\mathrm{ns}}$ & $0.035^{* * *}$ & $0.115^{* * *}$ & $0.489^{* * * *}$ & $4.44^{\mathrm{ns}}$ & $-0.376^{\mathrm{ns}}$ \\
\hline$\beta_{2}$ & - & $0.037^{* * * *}$ & $0.088^{\text {**** }}$ & $0.376^{* * * *}$ & - & $-4.450^{*}$ \\
\hline$\beta_{3}$ & $38.45^{* *}$ & $0.107^{* * * *}$ & $0.191^{* * *}$ & $0.978^{* * * *}$ & $13.54^{* * *}$ & $4.533^{*}$ \\
\hline$\beta_{11}$ & - & - & - & $0.100^{*}$ & - & $0.328^{\mathrm{ns}}$ \\
\hline$\beta_{22}$ & - & - & - & - & - & $-2.854^{\mathrm{ns}}$ \\
\hline$\beta_{33}$ & $-31.29^{* * *}$ & - & - & - & $-9.34^{* *}$ & $-11.163^{* * * *}$ \\
\hline$\beta_{12}$ & - & - & - & $0.197^{* *}$ & - & $-5.375^{\mathrm{ns}}$ \\
\hline$\beta_{13}$ & $-18.63^{\mathrm{ns}}$ & - & $0.068^{*}$ & $0.256^{* * * *}$ & $-7.71^{*}$ & $-14.375^{* * *}$ \\
\hline$\beta_{23}$ & - & - & $0.065^{*}$ & $0.255^{* * *}$ & - & $2.875^{\mathrm{ns}}$ \\
\hline model & $* * *$ & $* * *$ & $* * *$ & 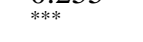 & $* * *$ & ** \\
\hline linear & $* *$ & $* * *$ & $* * *$ & $* * * *$ & **** & $\mathrm{ns}$ \\
\hline quadratic & ** & - & - & $*$ & $* *$ & ** \\
\hline cross-product & ns & - & ** & $* * *$ & * & $* *$ \\
\hline$R^{2}$ & 0.73 & 0.93 & 0.94 & 0.99 & 0.81 & 0.92 \\
\hline $\operatorname{Adj}-R^{2}$ & 0.65 & 0.92 & 0.91 & 0.99 & 0.75 & 0.82 \\
\hline Lack-of-fit & $0.344^{\mathrm{ns}}$ & $0.470^{\mathrm{ns}}$ & $0.447^{\mathrm{ns}}$ & $0.216^{\mathrm{ns}}$ & $0.571^{\mathrm{ns}}$ & $0.123^{\mathrm{ns}}$ \\
\hline
\end{tabular}

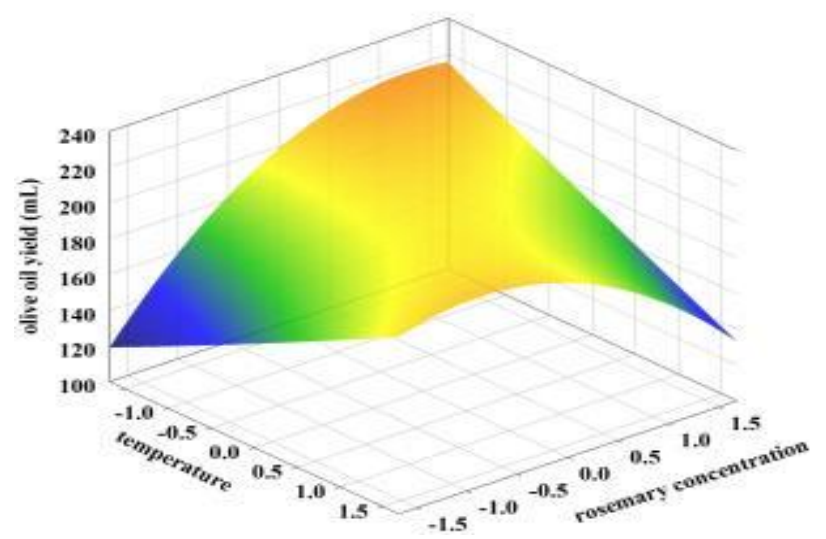

Figure 1 Change in oil yield under the effects of temperature and rosemary concentration at a constant time of $50 \mathrm{~min}$.

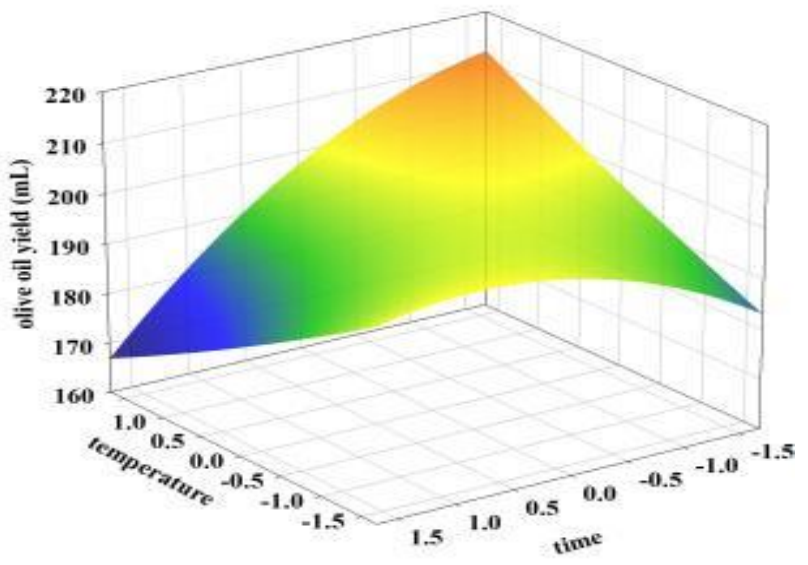

Figure 2 Change in oil yield under the effects of temperature and time at a constant rosemary amount of $1 \%$. 
Phenolic content and radical scavenging activity: Total phenolic content of olive oil was also examined, since being one of the important factors revealing functional potential. Meanwhile to figure out antioxidant characteristic of olive oil, free radical scavenging activities of sample was also determined. Our results indicated the presence of strong relation between total phenolic content and free radical scavenging activity of oil sample. Changes in these two parameters with rosemary amount were fairly similar and compatible with each other (Table 4 ). Table 4 showed that only rosemary amount significantly affected total phenolic content and free radical scavenging activity $(\mathrm{P} \leq 0.05)$, whereas malaxation conditions (temperature and time) were not important $(\mathrm{P}>0.05)$, except interaction of temperature with rosemary amount for free radical scavenging activity. To figure out change of total phenolic content and free radical scavenging activity of oil sample with rosemary amount, Figure 3 and 4 were drawn, respectively. At the lowest studied temperature, increasing rosemary amount caused an increase in total phenolic content and free radical scavenging activity of oil sample (Figure 3 and 4). Although no available data relevant to change of total phenolic content and free radical scavenging activity of olive oil with aromatization process in malaxation step was presented, the following studies were thought to provide related information about temperature and time effects during kneading process. Kalua et al. (2006) and Kalua et al. (2007) reported compatible results in their two different studies where no significant change in phenolic content of olive oil sample was observed with changing temperature and time of malaxation step. Moreover adverse effect of temperature on total phenolic content was also reported by Parenti et al. (2008) in which temperature higher than $27^{\circ} \mathrm{C}$ adversely affected the transition of phenolics to olive oil.

Pigments of aromatized olive oil: The unique color of olive oil is due to its pigment content including carotenoids, chlorophyll, and pheophytins (MínguezMosquera, 1993). Chlorophyll and pheophytin are green pigments of olive oil. Chlorophyll acts as an antioxidant in dark, but this pigment and its derivative, pheophytin (Mínguez-Mosquera, 1993), promote formation of oxygen radicals and accelerate oxidation under light (Cichelli and Pertesana, 2004; Lanfer-Marquez et al., 2005). Carotenoids another pigment group is responsible from yellow to red color and has antioxidant activity which prolongs shelf-life of oil product. Aromatic plants are good source of pigments including chlorophyll, pheophytin and carotenoids (soluble in oil).

Migrations of three pigment groups from olive fruit and herb to oil were investigated under effects of studied parameters (temperature and time of malaxation and rosemary amount). Process parameters significantly affected these all pigments' transitions to olive oil during malaxation step of aromatized olive oil production $(\mathrm{p} \leq$ 0.05 , Table 4). Figure 5 showed the change of total carotenoid content of oil sample under effects of rosemary and temperature. Total carotenoid content of oil sample increased with increases in both process parameters.
Temperature dependent change in carotenoid content may be attributed to an increase in mass diffusivity of these compounds into extraction medium and to a decrease in oil viscosity. Most important process variable markedly affecting carotenoid content of olive oil was found to be rosemary addition, since rosemary itself was a good source of these pigments and during aromatization process, transition of its carotenoids to the olive oil also occurred parallel to those from olive fruits.

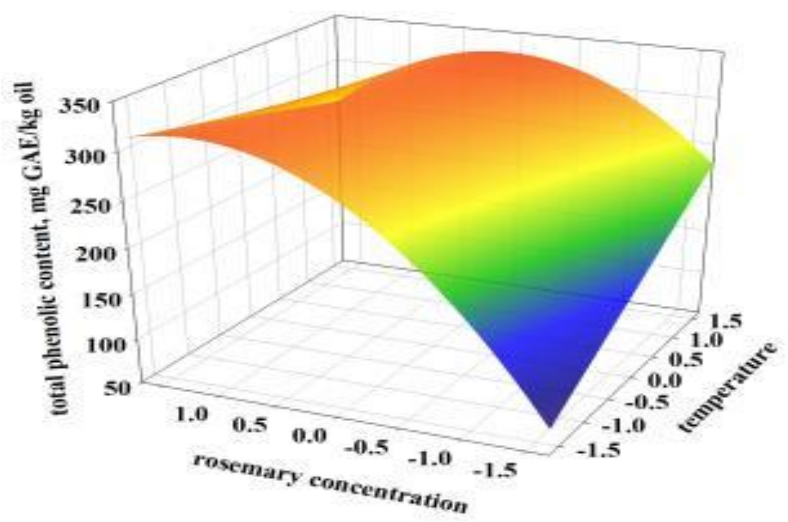

Figure 3 Change in total phenolic contents of olive oil with temperature and rosemary concentration at a constant time of 50 min.

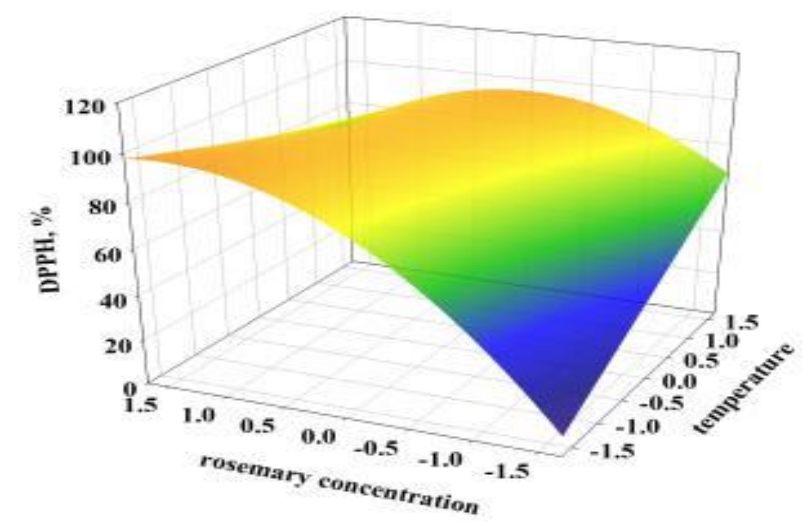

Figure 4 Change in free radical scavenging activity (DPPH) of olive oil with temperature and rosemary concentration at a constant time of $50 \mathrm{~min}$.

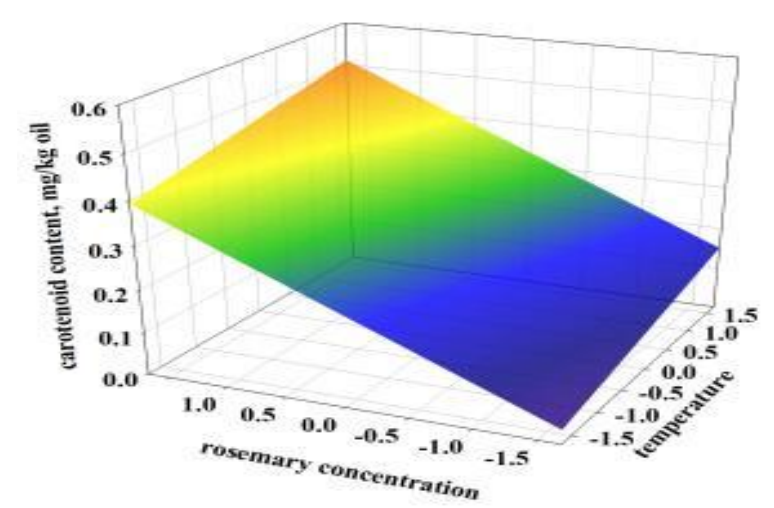

Figure 5 Change in total carotenoids content of olive oil under the effects of temperature and rosemary concentration at a constant time of $50 \mathrm{~min}$. 
Marked rise in carotenoid content of aromatized oil prepared by maceration of fresh rosemary was reported by Ayadi et al. (2009). This increasing trend of carotenoids was in accordance with our results. Malaxation time also displayed promoter effect on carotenoid content of oil sample (Table 4). Prolonged kneading may enable more pigment transition due to long contact time.

Green color pigments, chlorophylls were also under consideration at this study. Table 4 indicated strong relation between process variables and pigment transition to oil sample $(\mathrm{P} \leq 0.001)$. All parameters individually displayed promoter effects on chlorophylls content of oil sample. Interaction of rosemary with temperature and time were also significant $(\mathrm{P} \leq 0.05)$ (Table 4). An improvement in chlorophylls content of oil sample may be attributed to transition of these pigments from rosemary to oil and the effects of temperature and time on mass transfer phenomena taking place during malaxation step. Compared to non-aromatized oil sample, Ayadi et al. (2009) reported an increase in chlorophylls content of oil sample aromatized with rosemary maceration. This was compatible with our ones.

Another interested pigment group was pheophytins, since this pigment group was derivative of chlorophylls (Moyano et al., 2010) so their presence in olive oil was expected. Effects of process parameters on pheophytin a content of oil sample were investigated. Pheophytin a was seen to increase in oil sample depending on increasing process parameters (Table 4). An increase being related to amount of rosemary in malaxation step may be attributed to transition of rosemary originated pheophytin a to oil sample. Effects of malaxation temperature and time could be associated with their promoter effects on transformation of chlorophyll to pheophytin (pheophytinisation). Studies reported that pheophytinisation was accelerated by extraction conditions (Canjura and Schwartz, 1991; Psomiadou and Tsimidou, 2001). Canjura and Schwartz (1991) displayed that higher conversion of chlorophylls to pheophytin were at high temperature levels and the concentration of degradation product increased with prolonged process. Although these two pigment groups were changed with process parameters, chlorophyll and pheophytin content were found to remain in the reported ranges of these pigments for natural olive oils (Giuffrida et al., 2007).

Optimal process conditions for aromatization process: Optimization of food process is significant to evaluate process performance and to produce information for further works. In this manner present study was aimed to optimize aromatization process of olive oil. According to the best knowledge of authors this was the first time considering optimization of olive oil aromatization in terms of responses related to antioxidant potential and oil yield with some quality parameters. In this study all oil samples produced according to experimental design were found to be in the limits established for high quality extra virgin olive oil, so quality parameters were not considered for further optimization process. Oil yield, total phenolic content, free radical scavenging activity and total carotenoids were maximized, whereas chlorophylls and pheophytin a were not included in optimization due to their prooxidant activities under light. According to our findings, malaxation at $25^{\circ} \mathrm{C}$ for $84 \mathrm{~min}$ with $2 \%$ rosemary amount (Rosemary/olive paste; w/w) produced the highest levels of interested responses.

It could be concluded that the present study provided optimal conditions for maximum levels of total phenolics, total carotenoids and free radical scavenging activity as functional properties and the highest oil yield of aromatized olive oil by rosemary besides of high quality. Models displayed high success for prediction of experimental results according to model adequacy parameters $\left(\mathrm{R}^{2}, \mathrm{R}^{2}\right.$ adj). Any lack-of-fit was observed for all models $(\mathrm{P}>0.05)$. The results indicated marked rosemary dependent color change of olive oil due to high carotenoids, chlorophyll and pheophytin a contents of this herb and other process parameters promoted these pigments transition into oil product. Antioxidant potential of olive oil was enhanced with aromatization process and this improvement was dependent on herb. Malaxation conditions also showed significant effects. In this study improvement in oil yield was also obtained with addition of rosemary and controlled malaxation conditions.

According to results, optimal temperature for aromatization of olive oil by rosemary was in the range of that level defined for cold press producing high quality olive oil. Thus aromatization process with different olive cultivars and herbs should be optimized in terms of process conditions to obtain product having both high quality and antioxidant potential.

\section{References}

Abenoza M, Benito M, Saldaña G, Álvarez I, Raso J, SánchezGimeno A. 2013. Effects of pulsed electric field on yield extraction and quality of olive oil. Food Bioprocess Tech, 6(6): 1367-1373.

Aguilera MP, Beltran G, Sanchez-Villasclaras S, Uceda M, Jimenez A. 2010. Kneading olive paste from unripe 'Picual'fruits: I. Effect on oil process yield. J Food Eng, 97(4): 533-538.

Alimentarius C. 2001. Codex standard for olive oil, virgin and refined, and for refined olive-pomace oil. Codex stan33-1981.

AOCS. 1989. Official Methods and Recommended Practices of the American Oil Chemists' Society. 4th. Champaign, Illinois, U.S.A.

AOCS. 1999. Official Methods and Recommended Practices of the American Oil Chemists' Society. 5th. Champaign, Illinois, U.S.A.

Ayadi M, Grati-Kamoun N, Attia H. 2009. Physico-chemical change and heat stability of extra virgin olive oils flavoured by selected Tunisian aromatic plants. Food Chem Toxicol, 47(10): 2613-2619.

Boskou D, Blekas G, Tsimidou M. 2006. Olive oil composition. In: Boskou, D (Ed.). Olive oil: Chemistry and technology. 2. Champaign, Illinois: AOCS Press. pp. 41-73.

Canjura FL, Schwartz SJ. 1991. Separation of chlorophyll compounds and their polar derivatives by high-performance liquid chromatography. J Agric Food Chem, 39(6): 1102-1105.

Chipault J, Mizuno G, Hawkins J, Lundberg W. 1952. The antioxidant properties of natural spices. J Food Sci, 17(1-6): 4655.

Cichelli A, Pertesana GP. 2004. High-performance liquid chromatographic analysis of chlorophylls, pheophytins and carotenoids in virgin olive oils: chemometric approach to variety classification. J Chromatogr A, 1046(1): 141-146. 
Clodoveo ML. 2012. Malaxation: Influence on virgin olive oil quality. Past, present and future-An overview. Trends Food Sci Technol, 25(1): 13-23.

Damechki M, Sotiropoulou S, Tsimidou M. 2001. Antioxidant and pro-oxidant factors in oregano and rosemary gourmet olive oils. Grasas Aceites, 52(3-4): 207-213.

Di Giovacchino L. 1990. L'impiego del coadiuvante vegetale Silvacel nell'estrazione dell'olio dalle olive con i sistemi continui. Riv Ital Sostanze Gr, 67(1): 29-34.

Dorman HJD, Peltoketo A, Hiltunen R, Tikkanen MJ. 2003. Characterisation of the antioxidant properties of de-odourised aqueous extracts from selected Lamiaceae herbs. Food Chem, 83(2): 255-262.

Espínola F, Moya M, Fernández DG, Castro E. 2009. Improved extraction of virgin olive oil using calcium carbonate as coadjuvant extractant. J Food Eng, 92(1): 112-118.

Espínola F, Moya M, Fernández DG, Castro E. 2011. Modelling of virgin olive oil extraction using response surface methodology. Int J Food Sci Technol, 46(12): 2576-2583.

Fernández Valdivia DG, Espínola Lozano F, Moya Vilar M. 2008. The influence of different technological co-adjuvants on the quality and yield of virgin olive oil using response surfaces methodology. Grasas Aceites, 59(1): 39-44.

Gambacorta G, Faccia M, Pati S, Lamacchia C, Baiano A, La Notte E. 2007. Changes in the chemical and sensorial profile of extra virgin olive oils flavored with herbs and spices during storage. J Food Lipids, 14(2): 202-215.

Giuffrida D, Salvo F, Salvo A, La Pera L, Dugo G. 2007. Pigments composition in monovarietal virgin olive oils from various sicilian olive varieties. Food Chem, 101(2): 833-837.

Inarejos-García AM, Gómez-Rico A, Salvador MD, Fregapane G. 2009. Influence of malaxation conditions on virgin olive oil yield, overall quality and composition. Eur Food Res Technol, 228(4): 671-677.

Jacotot B. 1994. Olive oil: a food and medicine in one. Olivae, $5440-41$

Kalua CM, Bedgood DR, Bishop AG, Prenzler PD. 2006. Changes in volatile and phenolic compounds with malaxation time and temperature during virgin olive oil production. J Agric Food Chem, 54(20): 7641-7651.

Kalua C, Allen M, Bedgood D, Bishop A, Prenzler P, Robards K. 2007. Olive oil volatile compounds, flavour development and quality: A critical review. Food Chem, 100(1): 273-286.

Lagouri V, Boskou D. 1996. Nutrient antioxidants in oregano. Int J Food Sci Nutr, 47(6): 493-497.

Lanfer-Marquez UM, Barros RM, Sinnecker P. 2005. Antioxidant activity of chlorophylls and their derivatives. Food Res Int, 38(8): 885-891.

Malheiro R, Sousa A, Casal S, Bento A, Pereira JA. 2011. Cultivar effect on the phenolic composition and antioxidant potential of stoned table olives. Food Chem Toxicol, 49(2): 450-457.

Mínguez-Mosquera I. 1993. Clorofilas y carotenoides en tecnologia de alimentos Sevilla. Spain: Universidad de Sevilla.
Minguez-Mosquera MI, Rejano-Navarro L, Gandul-Rojas B, SanchezGomez AH, Garrido-Fernandez J. 1991. Color-pigment correlation in virgin olive oil. J Am Oil Chem Soc, 68(5): 332336.

Moldão-Martins M, Beirao-da-Costa S, Neves C, Cavaleiro C, Salgueiro L, Beirao-da-Costa ML. 2004. Olive oil flavoured by the essential oils of Mentha $\times$ piperita and Thymus mastichina $L$. Food Qual Prefer, 15(5): 447-452.

Morales MT, Luna G, Aparicio R. 2000. Sensory and chemical evaluation of winey-vinegary defect in virgin olive oils. Eur Food Res Technol, 211(3): 222-228.

Moyano MJ, Heredia FJ, Meléndez-Martínez AJ. 2010. The color of olive oils: The pigments and their likely health benefits and visual and instrumental methods of analysis. Compr Rev Food Sci F, 9(3): 278-291.

Nouhad A, Tsimidou M. 1998. Aceites de oliva aromatizados con hierbas y especias: ideas preconcebidas de los consumidores potenciales sobre las propiedades nutricionales y sensoriales de estos productos. Olivae: revista oficial del Consejo Oleícola Internacional(71): 56-62.

Parenti A, Spugnoli P, Masella P, Calamai L. 2008. The effect of malaxation temperature on the virgin olive oil phenolic profile under laboratory-scale conditions. Eur J Lipid Sci Technol, 110(8): 735-741.

Pokorny J, Kalinova L, Dysseler P. 1995. Determination of chlorophyll pigments in crude vegetable oils: Results of a collaborative study and the standardized method (Technical Report). Pure Appl Chem, 67(10): 1781-1787.

Psomiadou E, Tsimidou M. 2001. Pigments in Greek virgin olive oils: occurrence and levels. J Sci Food Agric, 81(7): 640-647.

Rached MB, Abdallah M, Guerfel M. 2014. Compositional quality of Zalmati virgin olive oil: Effect of the aromatization process with rosemary essential oils (Rosmarinus officinalis L.). Afr J Agric Res, 9(44): 3276-3282.

Ranalli A, Pollastri L, Contento S, Iannucci E, Lucera L. 2003a. Effect of olive paste kneading process time on the overall quality of virgin olive oil. Eur J Lipid Sci Technol, 105(2): 5767.

Ranalli A, Pollastri L, Contento S, Lucera L, Del Re P. 2003b. Enhancing the quality of virgin olive oil by use of a new vegetable enzyme extract during processing. Eur Food Res Technol, 216(2): 109-115.

Singleton VL, Rossi JA. 1965. Colorimetry of total phenolics with phosphomolybdic-phosphotungstic acid reagents. Am J Enol Vitic, 16(3): 144-158.

Stark AH, Madar Z. 2002. Olive oil as a functional food: epidemiology and nutritional approaches. Nutr Rev, 60(6): 170176.

Tsimidou M. 1998. Polyphenols and quality of virgin olive oil in retrospect. Ital J Food Sci, 10(2): 99-116. 